\title{
ANALISIS KINERJA SIMPANG GENDENGAN SURAKARTA MENGGUNAKAN PROGRAM SIMULASI PTV VISSIM
}

\author{
Safira Hana Pradipta ${ }^{1)}$, Budi Yulianto ${ }^{2)}$, Setiono ${ }^{3)}$ \\ 1)Mahasiswa Fakultas Teknik, Prodi Teknik Sipil, Universitas Sebelas Maret \\ 2)Pengajar Fakultas Teknik, Prodi Teknik Sipil, Universitas Sebelas Maret \\ Jl. Ir. Sutami No.36A, Kentingan, Surakarta 57126; Telp. (0271) 647069, Fax 634524 \\ Email: hanapradiptasafiraa@student.uns.ac.id
}

\begin{abstract}
In the southernmost section of Brigien Slamet Riyadi Street, traffic flow changes to a contraflow bus lane for BST (Solo Trans Bus). The Gendengan intersection is one of the intersections affected by the contraflow bus lane. That because of cycle time increase in high traffic volume that makes the queue length and vebicle delays increase. The purpose of this research is to analyze the Gendengan Intersection system fixed-time controller in existing conditions performance. The modeling in this study uses the PTV Vissim simulation program because it is a simulation model that can analyze traffic performance with output close to field conditions. Calibration and validation are carried out to prove that there is no significant difference between the results of the output model and the results of field observations. The output result of the Gendengan Intersection model is close to the observation results, that is the results of the GEH test $<5$ on traffic flow, the result of the $t$-test is $t$ count $<t$ table on the queue length, and the relative difference test results show a percentage difference of $6 \%$ on the travel time. From these results, the conclusion is the model was calibrated and validated. The results of the analysis of the performance of the intersection are the average queue length for each arm is 34.3 meters, the travel time is 161 seconds, and the intersection delay is 57 seconds.
\end{abstract}

Keywords: Gendengan Intersection, intersection performance, PTV Vissim

\begin{abstract}
Abstrak
Jalan Brigjen Slamet Riyadi pada ruas paling selatan terdapat perubahan arus lalu lintas menjadi contraflow bus lane untuk BST (Bus Solo Trans). Simpang Gendengan merupakan salah satu simpang yang akan dipengaruhi oleh adanya contraflow bus lane tersebut, karena waktu siklus menjadi bertambah dengan volume arus lalu lintas yang besar sehingga panjang antrean dan tundaan kendaraan akan bertamabah. Penelitian ini bertujuan untuk menganalisis kinerja Simpang Gendengan yang menggunakan sistem fixed time controller pada kondisi eksisting. Pemodelan pada penelitian ini menggunakan program simulasi PTV Vissim karena merupakan model simulasi yang dapat menganalisis kinerja lalu lintas dengan hasil output mendekati kondisi lapangan. Untuk membuktikan tidak adanya perbedaan yang signifikan antara hasil output model dengan hasil observasi di lapangan kemudian dilakukan kalibrasi dan validasi. Hasil output model Simpang Gendengan mendekati hasil observasi dengan hasil uji GEH $<5$ pada arus lalu lintas, nilai thitung $<$ tabel pada panjang antrean, dan pada waktu perjalanan hasil uji perbedaan relatif menunjukkan nilai persentase perbedaan sebesar 6\%. Dari hasil tersebut dapat disimpulkan bahwa model terkalibrasi dan tervalidasi. Hasil analisis kinerja simpang yaitu pada panjang antrean rata-rata tiap lengan sebesar 34,3 meter, waktu perjalanan sebesar 161 detik, dan tundaan simpang sebesar 57 detik.
\end{abstract}

Kata Kunci : kinerja simpang, PTV Vissim, Simpang Gendengan

\section{PENDAHULUAN}

Transportasi merupakan peranan penting bagi kehidupan masyarakat untuk mempermudah pergerakan barang dan jasa. Saat ini dengan mudahnya pembelian kendaraan, serta ruas jalan yang semakin lebar banyak masyarakat yang lebih memilih menggunakan angkutan pribadi daripada menggunakan angkutan umum. Hal ini menimbulkan permasalahan transportasi yaitu kemacetan lalu lintas. Beberapa titik di Kota Surakarta juga sering terjadi kemacetan, terlebih saat jam puncak atau jam sibuk. Permasalahan ini disebabkan banyak terdapat jalanan di Kota Surakarta yang sempit dan letak geografis Kota Surakarta juga menjadi sebab kemacetan karena volume kendaraan yang melintas menjadi tinggi. Banyak masyarakat daerah sekitar Kota Surakarta masuk untuk bekerja ataupun hanya sekedar melintas untuk menuju kota lain. Hal ini terbukti dari tidak dapatnya mengakomodasi penambahan jumlah kendaraan karena faktor semakin padatnya tata guna lahan di sekitar jalan, khususnya di Jalan Brigjen Slamet Riyadi Surakarta.

Sepanjang Jalan Brigjen Slamet Riyadi merupakan pusat bisnis Kota Surakarta, seperti bank, hotel, pusat perbelanjaan, restoran internasional, hingga tujuan wisata dan hiburan. Pengaturan lalu lintas pada Jalan Brigjen Slamet Riyadi adalah oneway atau jalan satu arah yang dari Simpang Gendengan hingga Bundaran Tugu Gladak. Pada 24 Desember 2020, Pemerintah Kota Surakarta telah membenahi tata guna lahan pada Jalan Brigjen Slamet Riyadi. Dimana arus lalu lintas ruas jalan paling selatan diubah menjadi contra flow bus lane untuk BST (Bus Solo Trans) dan 
semua parkir on-street menjadi parkir paralel dengan pengaturan sudut parkir $0^{\circ}$. Adanya penerapan contra flow bus lane terdapat simpang-simpang di Jalan Brigjen Slamet Riyadi yang terpengaruh. Simpang Gendengan merupakan salah satu simpang yang akan dipengaruhi oleh adanya contra flow bus lane tersebut. Simpang Gendengan terdiri dari Jalan Brigjen Slamet Riyadi, Jalan Dr. Wahidin, dan Jalan Doktor Moewardi. Keempat kaki simpang memiliki arus lalu lintas yang tinggi dilengkapi dengan sinyal lampu lalu lintas menggunakan sistem fixed time controller.

Penelitian ini bertujuan untuk menganalisis kinerja Simpang Gendengan dengan adanya perubahan pada waktu siklus. Kajian analisis kinerja Simpang Gendengan dilakukan dengan menggunakan program simulasi PTV Vissim. Program simulasi PTV Vissim merupakan perangkat lunak untuk memodelkan kondisi lapangan bentuk simulasi $2 \mathrm{D}$ dan 3D, berdasarkan perilaku pengguna jalan yang dapat mempermudah dalam menganalisis dan melakukan optimalisasi kinerja simpang bersinyal. Untuk mendapatkan hasil yang akurat dan mendekati kenyataan maka dibutuhkan proses kalibrasi dan validasi pada model yang dibuat.

\section{METODE}

\section{Kalibrasi Model Lalu Lintas}

Kalibrasi pada model adalah proses untuk menyesuaikan parameter driving behavior yang dilakukan secara berulang agar nilai hasil simulasi sesuai dengan data hasil observasi di lapangan. Dalam penelitian ini, jumlah arus lalu lintas di lengan-lengan simpang digunakan sebagai variabel pembanding kesesuaian antara hasil simulasi dan data hasil observasi lapangan (Yulianto B dan Setiono, 2013). Nilai GEH dihitung menggunakan persamaan [1] dan detail hasil perhitungan disajikan pada Tabel 1 .

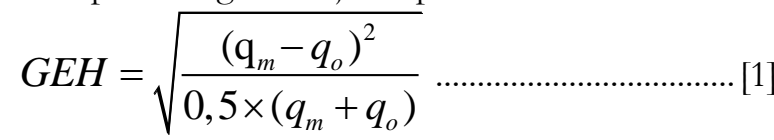

$$
\begin{aligned}
& \text { dengan: } \\
& \mathrm{q}_{\mathrm{m}}=\text { arus lalu lintas hasil Model } \\
& \mathrm{q}_{\mathrm{o}} \quad=\text { arus lalu lintas hasil Observasi }
\end{aligned}
$$

Tabel 1. Kesimpulan dari hasil perhitungan rumus statistik GEH (Oregon Departement of Transportation, 2011)

\begin{tabular}{cc}
\hline Nilai GEH & Keterangan \\
\hline GEH $<5,0$ & Diterima \\
$5,0 \leq \mathrm{GEH} \leq 10$ & Peringatan: kemungkinan model error atau data buruk \\
GEH $>10$ & Ditolak \\
\hline
\end{tabular}

\section{Validasi Model Lalu Lintas}

Validasi model adalah proses untuk menentukan apakah model simulasi lalu lintas yang dibuat dapat merepresentasikan kenyataan yang ada dengan akurat. Model simulasi lalu lintas dikatakan valid apabila keluaran hasil output model mendekati data hasil observasi di lapangan. Dalam penelitian ini, kinerja simpang yaitu waktu perjalanan (detik) dan panjang antrean kendaraan (meter) digunakan sebagai variabel pembanding antara hasil pemodelan dengan hasil observasi (Yulianto B dan Setiono, 2013).

Validasi pada panjang antrean menggunakan metode uji T. Uji T digunakan untuk menentukan probabilitas linearitas data terkait, menentukan apakah hasil pengukuran dapat dibandingkan secara statistik dengan nilai standar, dan juga untuk membandingkan dua alat secara statistik untuk menentukan apakah sama atau tidak. Uji T dinyatakan diterima apabila nilai thitung lebih kecil daripada nilai $t_{\text {tabel }}\left(t_{\text {hitung }}<t_{\text {tabel }}\right)$. Nilai Uji T dihitung menggunakan persamaan [2] dengan rumus S dijelaskan pada persamaan [3].

$$
\begin{aligned}
& t=\frac{\bar{x}_{1}-\bar{x}_{2}}{s \sqrt{\frac{1}{n_{1}}}-\frac{1}{n_{2}}} \\
& \text { Keterangan: } \\
& \mathrm{x}_{1}=\text { rata-rata data set pertama } \\
& \mathrm{x}_{2}=\text { rata-rata data set kedua } \\
& \mathrm{n}=\text { jumlah data } \\
& \mathrm{s} \quad=\text { standar deviasi dengan rumus pada persamaan }
\end{aligned}
$$




$$
S=\sqrt{\frac{\left(\mathrm{n}_{1}-1\right) s_{1}^{2}+\left(n_{2}-1\right) s_{2}^{2}}{n_{1}+n_{2}-2}}
$$

Validasi pada waktu perjalanan menggunakan uji kesesuaian perbedaan relative. Perbedaan relatif adalah perbedaan yang diukur dengan membandingkan nilai perbedaan mutlak dengan nilai observasi sehingga tidak memiliki satuan (unit). Nilai perbedaan mutlak dapat dihitung dengan persamaan [4] berikut.

Perbedaan Relatif $=\frac{\text { Nilai Model-Nilai Obeservasi }}{\text { Nilai Observasi }}$..... [4]

\section{Pengumpulan Data}

Pengumpulan data primer pada penelitian ini dilakukan beberapa survei lapangan. Survei yang dilakukan adalah inventarisasi ruas jalan raya dan simpang, pencacahan lalu lintas, kecepatan kendaraan, dan panjang antrean, survei waktu perjalanan, Pelaksanaan survei dilakukan pada jam sibuk (peak hour) yaitu pukul 07.00-09.00 dan didapat jam puncak pada pukul 07.30-08.30 dengan lokasi di Simpang Gendengan yang terdiri dari ruas Jalan Slamet Riyadi (lengan barat dan timur), Jalan Dr.Wahidin (lengan selatan, dan Jalan Dr. Moewardi (lengan utara). Berikut lokasi simpang dan arah arus lalu lintas dapat dilihat pada Gambar 1.

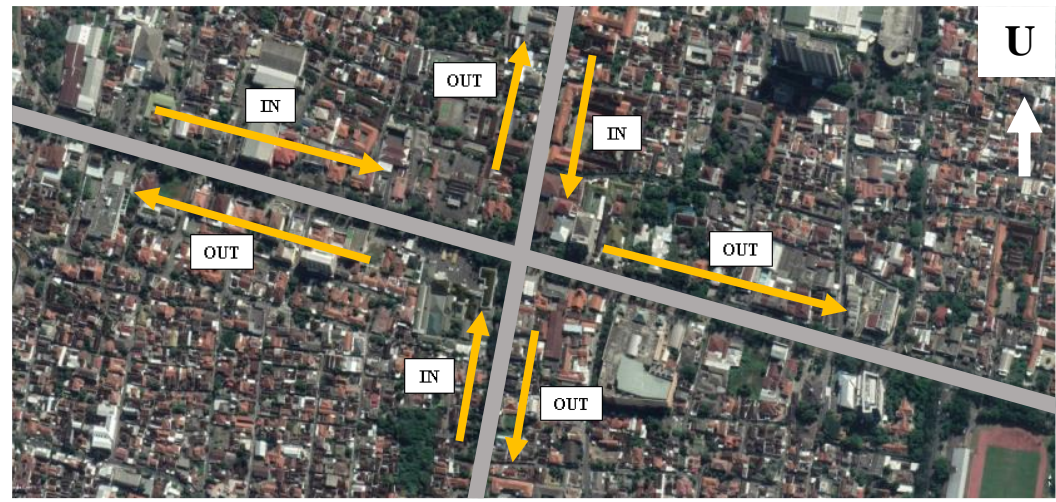

Gambar 1. Geometri simpang gendengan dan pergerakan arus lalu lintas

Pengumpulan data sekunder berdasarkan data yang didapatkan dari Dinas Perhubungan Kota Surakarta. Pengoperasian lampu APILL pada Simpang Gendengan menggunakan Fixed Time Controller (FTC) dengan empat fase. Berikut diagram fase pergerakan Simpang Gendengan disajikan pada Gambar 2.
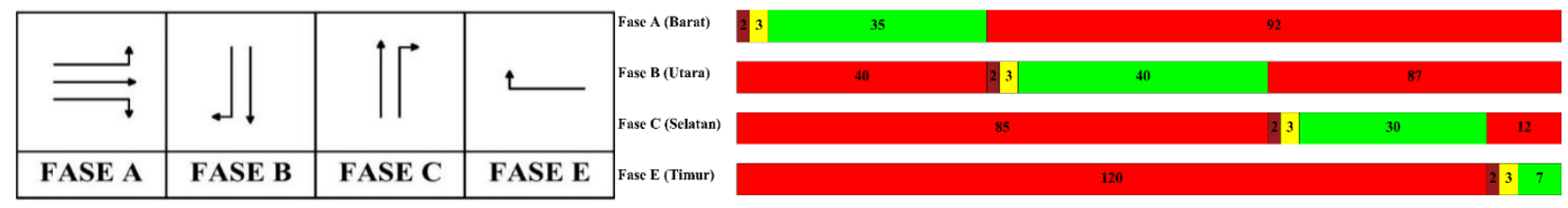

Gambar 2. Fase pergerakan dan waktu siklus

Gambar 2 menunjukkan pergerakan simpang Gendengan mempunyai empat fase dengan pembagian yaitu fase A merupakan pergerakan dari lengan barat dengan waktu hijau 35 detik; fase B merupakan pergerakan dari lengan utara dengan waktu hijau 40 detik; fase $C$ merupakan pergerakan dari lengan selatan dengan waktu hijau 30 detik; dan fase E merupakan pergerakan dari lengan timur untuk contraflow bus lane dengan waktu hijau sebesar 7 detik.

\section{Pemodelan pada PTV Vissim}

PTV Vissim merupakan program mikrosimulasi untuk melakukan perencanaan, analisis, dan optimalisasi aliran lalu lintas yang dikembangkan oleh PTV (Planung Transport Verkehr AG) yang berasal dari Jerman. Program simulasi PTV Vissim mampu melakukan simulasi kendaraan pribadi, transportasi umum, aliran arus lalu lintas multi moda, dan rekayasa pedestrian yang mana dapat dikalibrasi berdasarkan perilaku masing-masing. Blok-blok penyusun program simulasi PTV Vissim tersebut yaitu: 
1. blok infrastruktur digunakan untuk membuat model infrastruktur lalu lintas seperti jalan raya, rel dan fasilitas parkir, jalur transportasi publik yang sekaligus menjadi daerah asal dan tujuan perjalanan,

2. blok lalu lintas digunakan untuk melakukan pengaturan teknis kendaraan seperti volume kendaraan dan proporsi kendaraan serta digunakan juga untuk mengatur spesifikasi arus lalu lintas seperti penentuan rute perjalanan dan pembebanan jalan,

3. blok kontrol berisi elemen untuk melakukan kontrol lalu lintas, seperti mendefinisikan pemberhentian empat arah, aturan prioritas utama / minor dengan waktu antara tertentu, dan pengaturan sinyal lalu lintas,

4. blok output merupakan blok yang menangani semua jenis output data. Dalam blok ini akan dilakukan pemrosesan data yang disediakan oleh tiga blok utama sebelumnya. Output dapat dihasilkan selama simulasi baik sebagai kendaraan animasi dan status kontrol lalu lintas atau sebagai data statistik pembacaan detektor dan status kendaraan yang disajikan dalam kotak dialog.

Data yang diperoleh dari survei di lapangan selanjutnya digunakan untuk membuat model pada program simulasi PTV Vissim yang selanjutnya digunakan sebagai pembanding dengan hasil output model. Membuat model pada program simulasi PTV Vissim dengan menyesuaikan parameter-parameter driving behavior yang diubah secara berulang agar nilai hasil output mendekati data hasil observasi lapangan. Kemudian dilakukan run sebanyak 5 kali dengan nilai random seed yang berbeda untuk menghasilkan output yang meyakinkan.

\section{HASIL DAN PEMBAHASAN}

\section{Volume dan Komposisi}

Volume lalu lintas merupakan jumlah kendaraan yang melewati simpang atau ruas jalan dalam satu interval waktu, kemudian dilakukan perhitungan komposisi lalu lintas untuk mengetahui persentase tiap jenis kendaraan penyusun lalu lintas pada simpang. Data volume dan komposisi lalu lintas dapat dilihat pada Gambar 3.
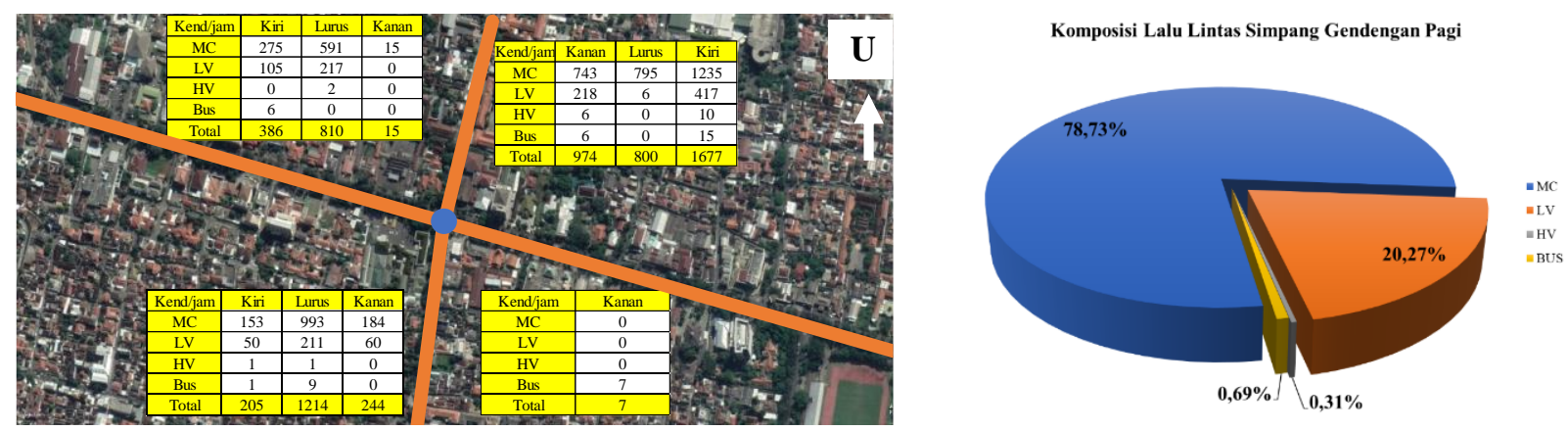

Gambar 3. Volume dan komposisi lalu lintas pada jam puncak

Volume dan komposisi lalu lintas yang menyusun Simpang Gendengan berdasarkan survei yaitu didominasi oleh motorcycle (MC) dengan persentase $78,73 \%$ dan paling sedikit yaitu truck (HV) dengan persentase $0,31 \%$. Contohnya pada lengan simpang dari utara ke barat (belok kanan) jumlah MC sebesar 743 kendaraan, LV sebesar 218 kendaraan, HV sebesar 6 kendaraan dan Bus sebesar 6 kendaraan.

\section{Proporsi Pergerakan}

Proporsi kendaraan merupakan persentase jumlah kendaraan tiap arah pergerakan untuk masing-masing jenis kendaraan. Data proporsi pergerakan didapatkan dari hasil survei pencacahan lalu lintas. Detail persentase proporsi pergerakan kendaraan tiap lengan simpang pada jam puncak pagi disajikan pada Tabel 2.

Tabel 2. Persentase Proporsi Pergerakan Kendaraan pada Simpang Gendengan

\begin{tabular}{cccccccccc}
\hline \multirow{2}{*}{ Jenis Kendaraan } & \multicolumn{3}{c}{ Utara } & \multicolumn{3}{c}{ Barat } & \multicolumn{3}{c}{ Selatan } \\
\cline { 2 - 19 } & Kanan & Lurus & Kiri & Kiri & Lurus & Kanan & Kiri & Lurus & Kanan \\
\hline MC & 0.27 & 0.29 & 0.45 & 0.31 & 0.67 & 0.02 & 0.12 & 0.75 & 0.14 \\
LV & 0.34 & 0.01 & 0.65 & 0.33 & 0.67 & 0 & 0.16 & 0.66 & 0.19 \\
HV & 0.39 & 0 & 0.61 & 0.0 & 1 & 0 & 0.41 & 0.59 & 0 \\
BUS & 0.29 & 0 & 0.71 & 1.0 & 0 & 0 & 0.10 & 0.90 & 0 \\
\hline
\end{tabular}

Tabel 2 menunjukkan proporsi pergerakan kendaraan dari lengan utara, barat, dan selatan terdapat pergerakan ke kanan, lurus dan kiri. Contohnya pada persentase pergerakan dari lengan utara untuk MC pergerakan ke kanan 
sebesar 0,27, lurus sebesar 0,29, dan ke kiri sebeasar 0,45. Untuk pergerakan LV dari lengan utara ke kanan sebesar 0,34, lurus sebesar 0,01, dan ke kanan sebesar 0,65. Untuk pergerakan HV dari lengan utara ke kanan sebesar 0,39 dan ke kiri sebesar 0,61. Untuk pergerakan bus dari lengan utara ke kanan sebesar 0,29 dan ke kiri sebesar 0,71.

\section{Hasil Kalibrasi Model}

Setelah melakukan penyesuaian parameter-parameter tersebut, model di run sebanyak 5 kali dengan nilai random seed (RS) yang berbeda untuk menghasilkan output yang meyakinkan. Dalam penelitian ini, untuk mengetahui perbedaan secara signifikan antara hasil simulasi dan data hasil observasi jumlah arus lalu lintas di lengan tiap simpang digunakan sebagai variabel pembanding kesesuaian antara hasil simulasi dan data hasil observasi lapangan. Berikut hasil kalibrasi Simpang Gendengan disajikan pada Tabel 3.

Tabel 3. Hasil Kalibrasi

\begin{tabular}{|c|c|c|c|c|c|c|c|c|c|c|}
\hline \multirow{3}{*}{\multicolumn{2}{|c|}{$\begin{array}{c}\text { Arus Lalu } \\
\text { Lintas }\end{array}$}} & \multicolumn{6}{|c|}{ q Model } & \multirow{3}{*}{$\underset{\text { Observasi }}{\mathrm{q}}$} & \multirow{3}{*}{$\begin{array}{l}\text { Nilai } \\
\text { GEH }\end{array}$} & \multirow{3}{*}{ Keterangan } \\
\hline & & \multicolumn{5}{|c|}{ Run ke- } & \multirow{2}{*}{-Rata -Rata } & & & \\
\hline & & 1 & 2 & 3 & 4 & 5 & & & & \\
\hline Utara & & 3408 & 3481 & 3506 & 3465 & 3607 & 3493 & 3430 & 1,07 & OK \\
\hline Barat & Masuk & 1210 & 1176 & 1181 & 1204 & 1202 & 1195 & 1205 & 0,29 & OK \\
\hline Selatan & & 1617 & 1640 & 1638 & 1609 & 1594 & 1620 & 1652 & 0,79 & OK \\
\hline Utara & & 1440 & 1448 & 1443 & 1430 & 1409 & 1434 & 1585 & 3,89 & OK \\
\hline Barat & & 1132 & 1112 & 1127 & 1119 & 1129 & 1124 & 1172 & 1,42 & $\mathrm{OK}$ \\
\hline Selatan & Keluar & 759 & 768 & 821 & 796 & 841 & 797 & 815 & 0,63 & $\mathrm{OK}$ \\
\hline Timur & & 2698 & 2747 & 2666 & 2644 & 2778 & 2707 & 2715 & 0,15 & OK \\
\hline
\end{tabular}

Tabel 3 menunjukan bahwa nilai GEH arus lalu lintas pada jam puncak pagi di tiap lengan simpang kurang dari 5, sehingga uji statistik GEH dinyatakan diterima. Berdasarkan hasil tersebut maka base model pada jam puncak pagi dinyatakan terkalibrasi.

\section{Hasil Validasi}

Proses validasi dilakukan untuk menentukan apakah simulasi lalu lintas yang dibuat sesuai dengan kondisi lapangan dengan cara membandingan hasil simulasi dengan data hasil observasi. Variabel pembanding yang digunakan yaitu waktu perjalanan (detik) dan panjang antrean tiap interval 10 menit (meter). Model simulasi lalu lintas dikatakan valid apabila output yang dihasilkan mendekati data hasil observasi di lapangan. Uji kesesuaian yang digunakan pada panjang antrean adalah uji T. Hasil uji T panjang antrean tiap interval 10 menit pada jam puncak disajikan pada Tabel 4.

Tabel 4. Hasil uji $\mathrm{T}$

\begin{tabular}{|c|c|c|c|c|c|c|c|}
\hline \multirow{2}{*}{$\begin{array}{l}\text { Lengan } \\
\text { Simpang }\end{array}$} & \multirow{2}{*}{$\begin{array}{l}\text { Interval } \\
\text { Menit ke }\end{array}$} & \multicolumn{2}{|c|}{$\begin{array}{l}\text { Panjang Antrean } \\
\text { Maksimum }\end{array}$} & \multirow[t]{2}{*}{ thitung } & \multirow[t]{2}{*}{$t_{\text {tabel }}$} & \multirow[t]{2}{*}{$\mathbf{P}$} & \multirow[t]{2}{*}{ Keterangan } \\
\hline & & Model & Observasi & & & & \\
\hline \multirow{6}{*}{ Barat } & $07: 40: 52$ & 55 & 55 & \multirow{6}{*}{1,3753} & \multirow{6}{*}{2,2281} & \multirow{6}{*}{0,1991} & \multirow{6}{*}{ OK } \\
\hline & $07: 50: 52$ & 63 & 65 & & & & \\
\hline & $08: 00: 52$ & 69 & 55 & & & & \\
\hline & $08: 10: 52$ & 63 & 59 & & & & \\
\hline & $08: 20: 52$ & 61 & 59 & & & & \\
\hline & 08:30:52 & 60 & 59 & & & & \\
\hline \multirow{6}{*}{ Selatan } & $07: 41: 44$ & 56 & 57 & \multirow{6}{*}{$-2,00933$} & \multirow{6}{*}{2,2281} & \multirow{6}{*}{0,0723} & \multirow{6}{*}{ OK } \\
\hline & $07: 51: 44$ & 61 & 63 & & & & \\
\hline & 08:01:44 & 55 & 58 & & & & \\
\hline & $08: 11: 44$ & 58 & 64 & & & & \\
\hline & 08:21:44 & 58 & 61 & & & & \\
\hline & 08:31:44 & 59 & 62 & & & & \\
\hline
\end{tabular}

Tabel 4 menunjukan hasil thitung panjang antrean jam puncak pagi lengan barat dan lengan selatan kurang dari tabel dan $\mathrm{P}$ (two-tailed) $>0,005$ sehingga dinyatakan diterima, yang berarti tidak adanya perbedaan signifikan antara panjang antrean maksimum output simulasi dengan data hasil observasi lapangan pada jam puncak pagi. 
Uji kesesuaian yang digunakan pada waktu perjalanan adalah uji perbedaan relatif. Hasil uji perbedaan waktu perjalanan pada jam puncak pagi disajikan pada Tabel 5.

Tabel 5. Hasil waktu perjalanan

\begin{tabular}{|c|c|c|c|c|}
\hline \multirow[t]{2}{*}{ Asal-Tujuan Perjalanan } & \multicolumn{2}{|c|}{$\begin{array}{c}\text { Waktu Perjalanan Rata- } \\
\text { rata (detik) }\end{array}$} & \multirow{2}{*}{$\begin{array}{c}\text { Persentase } \\
\text { Perbedaan Relatif }\end{array}$} & \multirow[t]{2}{*}{ Keterangan } \\
\hline & Model & Observasi & & \\
\hline Barat-Timur & 152 & 143 & $6 \%$ & OK \\
\hline
\end{tabular}

Tabel 5 diatas menunjukan hasil persentase perbedaan relatif waktu perjalanan pada jam puncak pagi dari barat menuju timur sebesar 6\% sehingga uji perbedaan relatif dinyatakan diterima.

\section{Hasil Analisis Kinerja Simpang}

Proses analisis kinerja Simpang Gendengan kondisi eksisting menggunakan hasil output yang didapatkan dari proses run terhadap simulasi Simpang Gendengan kondisi eksisting. Parameter kinerja simpang yang digunakan dalam analisis adalah panjang antrean, waktu perjalanan dan tundaan simpang. Hasil analisis kinerja simpang Gendengan dapat dilihat pada Tabel 6 - Tabel 8

Tabel 6. Panjang Antrean Hasil Simulasi Model

\begin{tabular}{lcccccc}
\hline \multirow{2}{*}{$\begin{array}{c}\text { Lengan Sim- } \\
\text { pang }\end{array}$} & \multicolumn{6}{c}{ Panjang Antrean Model (meter) } \\
\cline { 2 - 6 } \multicolumn{1}{c}{} & $\mathbf{1}$ & $\mathbf{2}$ & $\mathbf{3}$ & $\mathbf{4}$ & $\mathbf{5}$ & \multirow{2}{*}{ Rata-rata } \\
\hline Barat & 23 & 21 & 23 & 21 & 21 & 22 \\
Selatan & 22 & 23 & 24 & 20 & 23 & 22 \\
Utara & 38 & 56 & 74 & 45 & 81 & 59 \\
\hline
\end{tabular}

Tabel 6 menunjukkan hasil panjang antrean rata-rata model Simpang Gendengan. Panjang antrean lengan barat sebesar 22 meter, pada lengan selatan sebesar 22 meter dan pada lengan utara sebesar 59 meter.

Tabel 7. Waktu perjalanan hasil simulasi

\begin{tabular}{lccccccc}
\hline & & \multicolumn{6}{c}{ Waktu Perjalanan Rata-rata (detik) } \\
\cline { 3 - 6 } No & Rute Perjalanan & \multicolumn{5}{c}{ Run ke } & \multirow{2}{*}{ Rata-rata } \\
\cline { 3 - 6 } & & $\mathbf{1}$ & $\mathbf{2}$ & $\mathbf{3}$ & $\mathbf{4}$ & $\mathbf{5}$ & \\
\hline 1 & Barat - Selatan & 137 & 126 & 136 & 133 & 135 & 133 \\
2 & Barat - Utara & 120 & 114 & 116 & 116 & 117 & 117 \\
3 & Selatan - Barat & 127 & 123 & 125 & 125 & 125 & 125 \\
4 & Selatan - Utara & 184 & 186 & 186 & 183 & 186 & 185 \\
5 & Selatan - Timur & 176 & 179 & 175 & 177 & 180 & 177 \\
6 & Utara - Barat & 197 & 204 & 221 & 201 & 226 & 210 \\
7 & Utara - Selatan & 186 & 192 & 211 & 187 & 214 & 198 \\
8 & Utara - Timur & 146 & 159 & 163 & 150 & 164 & 156 \\
9 & Barat - Timur & 148 & 143 & 146 & 144 & 142 & 145 \\
\hline
\end{tabular}

Tabel 7 menunjukkan waktu perjalanan model Simpang Gendengan. Setelah dilakukan run 5 kali didapatkan hasil rata-rata waktu perjalanan tiap rute perjalanan sebagai berikut:

Barat menuju Selatan $\quad=133$ detik

Barat menuju Utara $\quad=117$ detik

Selatan menuju Barat $\quad=125$ detik

Selatan menuju Utara $\quad=185$ detik

Selatan menuju Timur $\quad=177$ detik

Utara menuju Barat $\quad=210$ detik

Utara menuju Selatan $\quad=198$ detik

Utara menuju Timur $=156$ detik

Barat menuju Timur $=145$ detik 
Tabel 8. Tundaan hasil simulasi

\begin{tabular}{cccccc}
\hline \multicolumn{5}{c}{ Tundaan (detik) } \\
\cline { 1 - 5 } Run ke- & \multirow{2}{*}{ Rata-rata } \\
\cline { 1 - 5 } $\mathbf{1}$ & $\mathbf{2}$ & $\mathbf{3}$ & $\mathbf{4}$ & $\mathbf{5}$ & \\
\hline 51 & 55 & 62 & 52 & 63 & 57 \\
\hline
\end{tabular}

Tabel 8 menunjukkan hasil dari tundaan simpang rata-rata Simpang Gendengan. Setelah dilakukan run sebanyak 5 kali dihasilkan tundaan sebesar 51 detik, 55 detik, 62 detik, 52 detik, dan 63 detik. Sehingga dapat diketahui bahwa tundaan rata-rata simpang pada Simpang Gendengan sebesar 57 detik.

\section{SIMPULAN}

Model Simpang Gendengan kondisi eksisting dapat terkalibrasi dan tervalidasi karena hasil perbandingan data volume arus lalu lintas, panjang antrean, dan waktu perjalanan pada model tidak terdapat perbedaan yang signifikan antara output dengan hasil observasi di lapangan. Hal tersebut dibuktikan dengan hasil uji statistik GEH pada arus lalu lintas menunjukan nilai kurang dari 5 , serta pada panjang antrean hasil uji T menunjukan nilai thitung lebih kecil daripada nilai $\mathrm{t}_{\text {tabel }}\left(\mathrm{t}_{\text {hitung }}<\mathrm{t}_{\text {tabel }}\right)$ dan $\mathrm{P}($ two-tailed $)>0,05$ dan pada waktu perjalanan hasil uji perbedaan relatif menunjukan nilai persentase perbedaan sebesar 6\%. Hasil analisis kinerja Simpang Gendengan dengan adanya perubahan waktu siklus yaitu pada panjang antrean rata-rata tiap lengan sebesar 34,3 meter, waktu perjalanan sebesar 161 detik, dan tundaan simpang sebesar 57 detik.

\section{REFERENSI}

Dirjen Bina Marga, 1990, "Panduan Survai dan Perhitungan Waktu Perjalanan Lalu Lintas", Departemen Pekerjaan Umum. Jakarta.

Putri, Nurjannah H., 2015, "Kalibrasi Vissim untuk Mikrosimulasi Arus Lalu Lintas Tercampur pada Simpang Bersinyal pada Simpang Tugu Yogyakarta", Universitas Gajah Mada. Yogyakarta.

Yulianto, B., \& Setiono., 2013, "Kalibrasi dan Validasi Mixed Traffic Vissim Model”, Media Teknik Sipil, pp.1-10. 